\title{
Palindromic rheumatism in two non-identical brothers with identical HLA including DR4
}

\author{
P HANNONEN, M HAKOLA, AND M OKA \\ From the Department of Medicine, Central Hospital, Jyväskylä, Finland
}

SUMMARY Two brothers, aged 52 and 44, who suffered from palindromic rheumatism (PR) for: 12 and 15 years were studied. The disease remained palindromic in the older brother, while $\stackrel{+}{+}$ chronic deformities developed early in the course of the disease in the younger. Their identical HLA locus was A9,Aw19(29); B12,Bw22; Cw1; DR1, DR4.

Key words: gold therapy.

The episodic form of recurring acute inflammatory attacks of joints and periarticular soft tissues by tender, sometimes reddish and hot swellings lasting from a few hours to one week was originally described by Hench and Rosenberg. ${ }^{1}$ They named this mode of presentation 'palindromic'. These pioneers, however, did not notice the conversion of the disorder to typical rheumatoid arthritis (RA) as later repeatedly shown and summarised by Mattingly. ${ }^{2}$ The pathogenesis of the swellings remains unknown, though extravascular activation of the complement cascade similar to that of angioneurotic oedema has been suggested. ${ }^{34}$ As to aetiology, both allergy and infection have been suggested. 5

Recently, Pines and coworkers recorded the association of familial juvenile chronic arthritis with the HLA antigen DR5. ${ }^{6}$ Furthermore, they suggested that PR might be a variant of juvenile chronic arthritis with a late onset and benign course. ${ }^{6}$

In this paper we describe two non-identical brothers suffering from typical PR and with identical HLA, including DR4.

\section{Case reports}

CASE 1

The patient is a police constable aged 52 . He had earlier suffered from acute nephritis, but recovered from it completely.

At the age of 40 he had the first attack of arthritis in the right shoulder lasting for 5 days and subsiding

Accepted for publication 20 September 1984.

Correspondence to Dr P Hannonen, Department of Medicine, Central Hospital, SF-40620 Jyväskylä, Finland. spontaneously. Thereafter the patient suffered hun $\stackrel{\widehat{\Im}}{\Im}$ dreds of similar attacks in shoulders, wrists, knees, $\vec{\oplus}$ and ankles, as well as in metacarpo- and metatar-or sophalangeal joints. The episodes were mostly afebrile and affected the joints concerned for aO period of hours to days. The patient attended several physicians, receiving various non-steroidaß anti-inflammatory drugs and intra-articular cortico-ه steroid injections. The attacks were infrequen between the years 1975 and 1981, then more을 frequent with intervals from a few days to 3 weeks. In November 1982 the attacks became more severe affecting several joints at the same time, with erythema of overlying skin and fever $\left(39^{\circ} \mathrm{C}\right)$. The erythrocyte sedimentation rate (ESR) increase of from 5 to $45 \mathrm{~mm} / \mathrm{h}$ and the serum level of C-reactive protein (CRP) from 8 to $36 \mathrm{mg} / \mathrm{l}$. The patient had been seropositive since 1981 (Waaler-Rose titre 1:512). Treatment with hydroxychloroquine $(4 \mathrm{mg} / \mathrm{o}$ $\mathrm{kg}$ body weight daily) was started. The attacks continued though they became milder, and ino February 1983 aurothiomalate injections (Myocrisin) were instituted. At that time the ESR had falleno to $9 \mathrm{~mm} / \mathrm{h}$ and the Waaler-Rose titre to $1: 256$. N Thereafter the patient remained seronegative. The స్ల attacks have not returned after a total dose of $400 \mathrm{mg}$ aurothiomalate. No erosions were found by $x$-ray. Extensive laboratory investigations to explainc the aetiology of the disease were negative. Thes HLA typing was A9,Aw19(29); B12,Bw22, Cw1; DR1, DR4.

CASE 2

The younger brother, aged 44 , is a mechanic. $\mathrm{He} \stackrel{\mathbb{D}}{\circ}$ suffered from palidromic joint episodes from 1969 to 
1972. The attacks affected mostly metacarpophalangeal joints, wrists, and elbows. The illness developed into a chronic polyarthritis in October 1972. Active synovitis with effusions was observed in both knees and elbows. Permanent destructive changes with restriction of movement developed in both elbows. The other joints were symptomless. The right knee was treated with osmic acid and the left one with local steroid. Thereafter the knees remained symptomless.

The patient was then well until the spring of 1983 , when acute palindromic attacks returned. At this time ankles and wrists as well as various small joints were affected. When seen for the first time in our hospital in September 1983 the patient was well, but later typical palindromic attacks were confirmed. The status of both elbows was similar to that in 1972, the $x$-rays showing advanced destructive changes. Therapy with gold was begun, and after a total dose of $500 \mathrm{mg}$ aurothiomalate had been administered the patient became symptomless, and he remained seronegative. The HLA typing was identical with that of the older brother (case 1), as also verified by negative mixed lymphocyte culture reaction (MLC).

\section{Discussion}

Palindromic rheumatism is not uncommon, comprising $1-2 \%$ of patients with inflammatory joint complaints. ${ }^{5}$ During follow up more than half of the patients become seropositive and about one third of them evolve into RA. ${ }^{25}$ Both infection and allergy, as well as stress, have been suggested as triggering extravascular activation of complement as the pathogenetic mechanism behind the clinical symptoms. On the other hand serum and synovial fluid complement, including $\mathrm{C} 1$ esterase inhibitor ${ }^{3} 7$ and serum circulating immune complex levels, ${ }^{8}$ have been reported to be normal. Furthermore, normal viral antibody titres to most common viruses were found in patients with PR. ${ }^{9}$ If symptomatic therapy with non-steroidal anti-inflammatory drugs (NSAIDs) and local steroids does not give relief to the patient, antirheumatic therapy with gold, ${ }^{2}$ antimalarials, ${ }^{10}$ and D-penicillamine ${ }^{11}$ have been reported to be effective. Since the pioneering report by Stastny on the association of RA with the HLA antigen Dw $4^{12}$ and the related $B$ cell antigen DR4, ${ }^{13}$ this has been repeatedly verified, except in Jews, who have a significant overrepresentation of Dw1 and DR1.13

There are only a few reports of the familial occurrence of PR. ${ }^{23}$ Recently, however, Pines and coworkers $^{6}$ described a family of four affected members (the mother and three children) plus the asymptomatic father who shared the tissue antigen
DR5 known to be overrepresented in patients with juvenile RA. All three children with identical HLA locus also shared DR4 with the healthy father. Nevertheless the authors suggested that PR might be a variant of juvenile chronic arthritis with relatively late onset and benign course. ${ }^{6}$

Our patients had identical HLA loci as indicated by negative MLC, including DR4. The deceased parents, so far as is known, had no symptoms of RA, nor had any of the four children of the older brother. The 56-year-old sister of the patients suffered from bronchial asthma and arthralgias without objective findings. Her HLA typing showed A3,A9; B12,Bw22; Cw1; DR3,DR4.

The course of the disease in our patients was fluctuating and relatively benign. The seronegative younger brother developed early chronic deformities. On the other hand the older brother, who was transiently seropositive, suffered from more fulminant attacks, but the disease remained non-erosive. The response to gold was excellent, which confirms the findings of Mattingly. ${ }^{2}$ The molecular mechanisms behind the acute manifestations of PR remain unresolved, though the activation of the complement cascade can lead to bradykinin formation. ${ }^{15}$ It appears to us that the HLA constitution of the patients is not of crucial importance in this process. The view that $P R$ is a variant of juvenile chronic arthritis is not supported by our findings. On the other hand, the PR patients with HLA-DR4 might be the ones most liable to develop chronic polyarthritis. These patients ought to be followed up thoroughly, and the therapy with antirheumatic drugs should be instituted promptly if indicated.

The authors are grateful to Dr Saija Koskimies, from the Finnish Red Cross Tissue Typing Laboratory, Helsinki, for the tissue typing of the patients.

\section{References}

1 Hench P S, Rosenberg E F. Palindromic rheumatism. Arch Int Med 1944; 73: 293-321.

2 Mattingly S. Palindromic rheumatism. Ann Rheum Dis 1966; 25: 307-17.

3 Wajed M A, Brown D L, Currey H L F. Palindromic rheumatism. Clinical and serum complement study. Ann Rheum Dis 1977; 36: 56-61.

4 Woo P, Cooper C, Harrison R, Ames N, Reeve S, Lachman $P$ J. Rheumatoid synovitis - a localised form of angioneurotic oedema. Ann Rheum Dis 1984; 43: 109-10.

5 Hardo H G. Palindromic rheumatism: a review. $J R$ Soc Med 1981; 74: 521-4.

6 Pines A, Kaplinsky N, Orgad S, Gazit E, Frankl O. Familial palindromic rheumatism: a possible association with HLA. Ann Rheum Dis 1983; 42: 631-3.

7 Williams M H, Sheldon P J H, Torrigiani G, Eisen V, Mattingly S. Palindromic rheumatism. Clinical and immunological studies. Ann Rheum Dis 1971; 30: 375-80. 
8 Thompson B, Mohammed I, Holborow E J, Currey H L F. Palindromic rheumatism. II. Failure to detect circulating immune complexes during acute episodes. Ann Rheum Dis 1979; 38: 329-31.

9 Mattingly S, Jones D W, Robinson W M, Williams R A, Dunn E C. Palindromic rheumatism. J R Coll Physicians Lond 1981: 15: $119-23$.

10 Golding D N. D-Penicillamine in palindromic rheumatism. $\mathrm{Br}$ Med $J$ 1976; ii: $1382-3$.
11 Huskisson E C. Treatment of palindromic rheumatism with Dpenicillamine. $\mathrm{Br}$ Med J 1976; ii: 979.

12 Stastny P. Mixed lymphocyte cultures in rheumatoid arthritis. $J$ Clin Invest 1976; 57: 1148-57.

13 Stastny $P$. Association of the B-cell alloantigen DRw4 with rheumatoid arthritis. $N$ Engl J Med 1978; 298: 869-71.

14 Schiff B. Mizrachi Y, Orgad S, Yaron M, Gazit E. Association of HLA-Aw31 and HLA-DR1 with adult rheumatoid arthritis. Ann Rheum Dis 1982; 41: 403-4.

15 Kaplan A P. Angioedema. N Engl J Med 1984; 310: 1662-3. 